\title{
A Internet como Ferramenta Colaborativa: O Exemplo da Construção do Marco Civil da Internet Brasileira
}

\author{
Ualdir Oliveira Santos Neto \\ Dept de Informática e Ciência da \\ Computação \\ Universidade do Estado do Rio de Janeiro \\ ualdir@gmail.com
}

\author{
Neide Santos \\ Dept de Informática e Ciência da \\ Computação \\ Universidade do Estado do Rio de Janeiro \\ neideeime.uerj.br
}

\begin{abstract}
Resumo
O uso público da Internet, no Brasil, começou há 15 anos e ainda não existe uma lei específica sobre o assunto. A necessidade de se estabelecer balizas sobre as responsabilidades dos diversos atores envolvidos foi um dos pontos fundamentais para o inicio do processo de regulamentação da Internet Brasileira. A partir dessa demanda da sociedade civil, o Ministério da Justiça em parceria com Centro de Tecnologia e Sociedade da Escola de Direito do Rio de Janeiro da Fundação Getulio Vargas, desenvolveram um processo colaborativo para a construção de um anteprojeto de lei denominado Marco Civil da Internet Brasileira. A idéia foi utilizar a própria Internet como meio para regulamentá-la. Para tanto, foi montado um processo colaborativo utilizando ferramentas da Web 2.0. O debate foi aberto para quem tivesse interesse no assunto e foram abordados temas como anonimato na rede, responsabilidades dos provedores e diretrizes governamentais para a inclusão digital. No final do processo, através compartilhamento do conhecimento coletivo obtido, foi possível identificar opiniões e sentimentos que servirão de base para o anteprojeto de lei da internet brasileira.
\end{abstract}

\footnotetext{
Abstract

Public use of the Internet in Brazil began 15 years ago and even now there is no specific law on the subject. The need to establish goals that provide a clear view of the responsibilities of various stakeholders were key points for the beginning of the process of regulating the Internet in Brazil. From this demand of civil society, the Ministry of Justice in partnership with the Center for Technology and Society of Law School of Rio de Janeiro - Fundação Getúlio Vargas, developed a collaborative process to build a draft bill called the Civil Framework for Brazilian Internet. The idea was to use the Internet itself as a means to regulate it. For that, we assembled a collaborative process using Web 2.0 tools. The purpose was that people involved in the process could argue about the objects of regulation. The debate, therefore, was open to anyone with interest in the subject enough for this to be connected to the network. During the discussions, were discussed as anonymity, providers' responsibilities and government guidelines for digital
}

inclusion. At the end, by sharing the collective knowledge, it was possible to identify feelings as a basis for the draft bill of the Brazilian Internet.

\section{Introdução}

As dificuldades de legislar sobre a Internet são inúmeras. A utilização de uma plataforma on-line para promover o debate público e criar um projeto de lei aceitável representa uma interessante tentativa de superar essa tarefa complexa. As tecnologias da chamada Web 2.0 podem ser muito proveitosas para apoiar este debate. Neste sentido, o objetivo deste artigo é apresentar o estado atual do projeto Marco Civil da Internet Brasileira e discutir como as tecnologias da Web 2.0 estão apoiando o projeto. Para atingir este objetivo, o trabalho está organizado da seguinte forma: na seção 2 é discutida a colaboração na rede, conceituada a Web 2.0, identificadas as tecnologias da Web 2.0 e discutidos os desafios Web para a gestão do conhecimento; na seção 3 é oferecida uma visão geral da importância da inclusão digital e descritas as políticas de e-governo no Brasil; na seção 4 são identificados os limites de abrangência do Marco Civil, descritas a experiência colaborativa no processo de elaboração do projeto de lei, bem como a participação popular no processo, identificado como outros países trataram a questão de regulamentação da Internet e apresentados o estágio atual e as percepções sobre o processo; e, por fim, no capítulo 5 são apresentadas as conclusões do trabalho.

\section{A Natureza Colaborativa da Rede}

A Internet vive em função da colaboração. Não existiria Internet se não houvesse compartilhamento. Ela mais do que nunca, nos últimos anos, vem demonstrando sua enorme capacidade de colaboração, com a consolidação da chamada Web 2.0. A Web 2.0 representa uma segunda fase na geração de serviços oferecidos através da Internet, e caracteriza-se pela ampliação das formas de produção cooperada e pelo compartilhamento das informações entre seus usuários. 


\subsection{Conceituando a Web 2.0}

A história da Web 2.0 começa com o episódio chamado de estouro da "bolha" da Internet, ocorrido no final do ano de 2001, quando se viu uma valorização exagerada de empresas Web operadas na bolsa tecnológica Nasdaq. Quando menos se esperava, investidores receosos do futuro destas empresas retiraram suas aplicações, e muitas dessas empresas entraram em crise financeira. Justamente neste contexto, nasce o conceito chamado "Web 2.0". Segundo Tim O'Reilly, a Web 2.0 representa a revolução dos negócios na indústria de computadores causada pela visão da Internet como uma plataforma e uma tentativa para entender as regras para o sucesso nessa nova plataforma. Ou seja: criar aplicativos que aproveitam os efeitos de rede para obter o melhor das pessoas que a usam, isto é o chamado "aproveitamento coletivo inteligência" [1]. Alguns dos princípios Web 2.0 são:

- A Web vista como plataforma;

- Inteligência coletiva;

- Os dados são o coração;

- Modelos de programação leve;

- Software acima do nível do dispositivo único;

- Rica experiência do usuário.

Se na primeira geração da Web os sites eram trabalhados como unidades isoladas, se passa agora para uma estrutura integrada de funcionalidades e conteúdo. Segundo O'Reilly, não há como demarcar precisamente as fronteiras da Web 2.0. Trata-se de um núcleo ao redor do qual gravitam princípios e práticas que aproximam diversos sites que os seguem. Um desses princípios fundamentais é trabalhar a Web como uma plataforma, isto é, viabilizando funções on-line que antes só poderiam ser conduzidas por programas instalados em um computador [1].

Outros fatores que conferem força é o desenvolvimento de um novo formato para a circulação de informações e formas de publicação através de processo coletivo para a organização e recuperação de documentos eletrônicos. Portanto, a Web 2.0 apresenta repercussões sociais importantes, que potencializam processos de trabalho coletivo, de troca afetiva, de produção e circulação de informações, de construção social e de conhecimento apoiada pela informática.

\subsection{Tecnologias da Web 2.0}

O conceito da Web 2.0 está intimamente amparado por um conjunto de tecnologias que surgindo durante esse novo período de visualização da Internet como uma plataforma de desenvolvimento. Naturalmente, qualquer aplicativo Web pode ser visto como software acima do nível de um único dispositivo. Afinal, mesmo a aplicação mais simples envolve pelo menos dois computadores: o que hospeda o servidor web e uma hospedagem no navegador [2]. Porém a Web 2.0 trouxe um conjunto de novas tecnologias, que permite muito mais dos usuários, tornando-os "co-desenvolvedores". Dessa forma os usuários não dependem mais de aplicações instaladas em suas máquinas para produzir conteúdos.

Estas aplicações, além disso, são muito mais leves e fáceis de serem utilizadas, flexíveis, acessíveis e culturalmente aceitáveis pelo usuário da rede, que passa de consumidor a ser o grande produtor de informação da Internet. Agora ele pode postar uma foto, um vídeo e deixar um comentário, criar link de suas informações prediletas e prover conteúdos. Há muitas ferramentas da Web 2.0 disponíveis:

Os blogs (abreviação de Web $\log s$ ) são revistas online ou diários, hospedados em site e muitas vezes distribuídos para outros sites ou leitores usando RSS (Really Simple Syndication). Permitem uma atualização rápida através dos chamados artigos posts.

Os mash-ups são agregações de conteúdos on-line a partir de fontes diferentes para criar um novo serviço. Um exemplo seria um programa que "puxa" apartamentos de anúncios de um site e os exibe em um mapa do Google para mostrar onde os apartamentos estão localizados.

As redes P2P (peer-to-peer) são uma arquitetura de sistemas distribuídos, caracterizadas pela descentralização das funções na rede, onde cada nó realiza tanto funções de servidor quanto de cliente. É uma técnica para o compartilhamento eficiente de arquivos (música, vídeos ou texto), quer sobre a Internet ou dentro de um grupo próximo de usuários. Ao contrário do método tradicional de armazenar um arquivo em uma máquina - que pode se tornar um gargalo, se as pessoas tentam acessá-lo de uma vez, P2P distribui arquivos em muitas máquinas, muitas vezes as dos próprios usuários. Alguns sistemas recuperaram 
arquivos através do recolhimento e montagem de peças através de diversas máquinas diferentes.

A tecnologia do RSS funciona como um agregador de conteúdo, e permite aos usuários da Internet se inscrever em sites que fornecem feeds RSS. Estes são tipicamente sites que mudam ou atualizam o seu conteúdo regularmente. Para isso, são utilizados feeds RSS que recebem estas atualizações e, desta maneira, o utilizador pode permanecer informado das atualizações em diversos sites sem precisar visitá-los um a um. Os RSS e permitem inscrições on-line para distribuição de notícias, blogs, podcasts ou outras informações.

Os podcasts são gravações de áudio ou vídeo multimídia a partir de um blog ou outros conteúdos. Eles são geralmente distribuídos através de um agregador, como iTunes.

As redes sociais referem-se a sistemas que permitem que os membros de um determinado site compartilhem suas habilidades, talentos, conhecimento ou preferências. Os exemplos comerciais incluem o Orkut, Facebook, LinkedIn, entre outros. Hoje algumas empresas já utilizam esses sistemas internamente para ajudar a identificar especialistas.

Os serviços Web (Web Services) são sistemas de software que tornam mais fácil a comunicação automática entre sistemas para passar informação de operações ou conduta. Por exemplo, um varejista e um fornecedor podem usar serviços da Web para se comunicar pela Internet e automaticamente atualizar seus sistemas.

Wikis, como a Wikipedia, são sistemas de publicação de colaboração. Eles permitem que muitos autores a contribuam para um documento on-line ou discussão.

Um conjunto novo de tecnologia de fácil utilização foi lançado e deu os contornos dessa nova rede, chamada de Web 2.0. Essas tecnologias contribuíram para a chamada inteligência coletiva e potencializou a área de gestão do conhecimento.

\subsection{Gestão do Conhecimento}

A Internet evolui para ser o principal meio de comunicação, informação e comércio, onde nós usuários somos os principais produtores e consumidores dos seus serviços. Ferramentas e tecnologias da Web 2.0 fornecem um meio para montagem e integração de aplicações distribuídas, formatos e conteúdos, tornando-se bem adequado para a gestão do conhecimento.

O surgimento e a rápida expansão das tecnologias de distribuição e divulgação de informações e conhecimento trouxeram para $\mathrm{o}$ foco as oportunidades de desenvolvimento baseado em redes de conhecimento, disseminação do conhecimento e o conhecimento das tecnologias de gestão e suas potenciais aplicações para melhorar a produtividade do trabalho de conhecimento.

"É preciso um trabalho sistemático sobre a qualidade do conhecimento e a produtividade do conhecimento nem sequer definido até agora. A capacidade de desempenho, se não a sobrevivência, de qualquer organização na sociedade do conhecimento estarão cada vez mais condicionadas sobre esses dois fatores. Mas também a capacidade de desempenho, se não a sobrevivência, do indivíduo na sociedade do conhecimento (Peter Drucker, A Era da Transformação Social, 1994).”

Para se manterem atualizadas e competitivas, as pessoas devem de forma eficiente e eficaz, localizar, capturar e compartilhar o seu conhecimento e competência. Isso exige cada vez mais tornar do conhecimento explícito e gravá-lo para facilitar a distribuição e reutilização.

O conhecimento é geralmente distinguido de dados e informações. Os dados representam observações ou fatos fora de contexto e, portanto, não diretamente significativo. Informação resulta da colocação de dados dentro de um contexto significativo, muitas vezes sob a forma de uma mensagem. O conhecimento é o que passamos a acreditar e com base no valor organizado da acumulação significativa de informação (mensagens), através da experiência, comunicação ou inferência. Conhecimento pode ser visto tanto como uma coisa para ser armazenada e manipulada, como um processo de conhecer e agir simultaneamente, conhecer isto é, aplicando a perícia. Como uma questão prática, as organizações precisam gerir conhecimento tanto como objeto e processo.

$\mathrm{O}$ conhecimento pode ser tácito ou explícito. $\mathrm{O}$ conhecimento tácito é entendido e aplicado informalmente, sendo difícil de articular, desenvolvido a partir da experiência direta e da ação e, normalmente, compartilhado através de conversas interativas, narração de histórias e experiências comuns. O conhecimento explícito, em contraste, pode ser mais preciso e formalmente articulado. Portanto, embora mais abstrato, pode ser mais facilmente codificado, documentado, transferidos ou compartilhados. O conhecimento explícito está desempenhando um grande papel cada vez mais nas sociedades, e é considerado por alguns como o mais importante fator de produção na economia do conhecimento. Imagine uma sociedade sem leis, manuais de procedimentos, a literatura do produto, ou software de computador [14].

A gestão do conhecimento explícito utiliza quatro recursos primários: (a) repositórios de conhecimento explícito; (b) refinarias para acumular, filtrar, gerenciar e distribuir esse conhecimento; (c) organização de papéis para executar e gerenciar o processo de refino; e, as tecnologias da informação para apoiar os repositórios e processos. A concepção de um repositório de conhecimento reflete a dois componentes básicos do conhecimento como um objeto: estrutura e conteúdo. Estruturas de conhecimento fornecem o contexto para interpretar o conteúdo acumulado. Se o repositório é concebido como uma plataforma de conhecimento, então muitos diferentes pontos de vista do conteúdo podem ser derivados de uma estrutura de repositório particular [14]. Um elevado grau de flexibilidade de visualização permite que os usuários alterem e combinem pontos de vista de forma dinâmica e interativa e mais facilmente aplicar os conhecimentos a novos contextos e circunstâncias. Neste ponto, o conhecimento como objeto torna-se o conhecimento como processo [14]. 
O elemento estrutural básico é a unidade do conhecimento, uma definida formalmente, um pacote de conteúdos de conhecimento central que pode ser rotulado, indexados, armazenados, recuperados e manipulados. $\mathrm{O}$ formato, tamanho e conteúdo do conhecimento unidades podem variar dependendo do tipo de conhecimento explícito armazenado e no contexto da sua utilização [13].

A refinaria representa o processo de criação e distribuição do conhecimento contido no repositório. Este processo inclui cinco fases:

- Aquisição: Informação e conhecimento sejam criados dentro da organização ou podem ser adquiridas a partir de diversas fontes internas e externas.

- Filtro: conhecimento adquirido, antes de ser adicionado ao repositório, é submetido a processos de agregação de valor (refino), tais como limpeza, rotulagem, indexação, classificação, abstraindo, padronização, integração e re-classificar.

- Armazenamento e recuperação: Esta fase de criação do repositório que possibilita a distribuição do conhecimento.

- Distribuição: Esta etapa representa os mecanismos utilizados para fazer o repositório de conteúdo acessível.

- Apresentação: O valor do conhecimento é influenciado pelo contexto da sua utilização. Capacidades devem ser fornecidas de forma flexível para organizar, selecionar e integrar o conteúdo de conhecimento.

A infraestrutura de tecnologia da informação deve fornecer uma estrutura perfeita para o fluxo de conhecimento explícito através de etapas do processo de refinação para permitir:

- Capturar conhecimento,

- Definir, armazenar, classificar, indexar e vincular objetos digitais correspondentes às unidades de conhecimento,

- Procurar e validar um conteúdo relevante,

- Apresentar conteúdos com flexibilidade suficiente para torná-lo significativo e aplicável em múltiplos contextos de uso.

As tecnologias da informação oferecem um ambiente potencialmente útil, em que a construção de um repositório multimídia para o conhecimento explícito é rico. A entrada é capturada por formas de atribuição de rótulos diferentes, categorias e índices a cada unidade de conhecimento. A estrutura é suficientemente flexível para criação de unidades de conhecimento, indexados e relacionados com as categorias que refletem a estrutura do conhecimento contextual e o conteúdo do conhecimento factual da sociedade, apresentada como subconjuntos flexíveis personalizáveis através de pontos de vista de forma dinâmica.

O uso efetivo da tecnologia da informação para comunicar conhecimento requer uma organização para compartilhar um contexto interpretativo. Quanto mais partes comunicadoras de conhecimento similar, formação e experiência, o conhecimento mais eficaz pode ser comunicado através de canais eletrônicos. Em um extremo, a divulgação dos fatos, o conhecimento explícito dentro de uma comunidade estável com um elevado grau de conhecimento compartilhado contextual pode ser realizado através do acesso a um repositório eletrônico central. No entanto, quando o contexto interpretativo compartilhado é moderado, ou a troca de conhecimento é menos explícita, ou a comunidade é frouxamente afiliada, em seguida, esses modos interativos eletrônicos ou e-mail debate bases de dados mais adequados. Quando o contexto não é bem comum e o conhecimento é basicamente tácito, comunicação e narração tornam-se uma experiência melhor com o suporte e os modos mais interativos ricos, tais como videoconferência ou a conversação face-face [14].

Portanto é possível aproveitar do conhecimento coletivo e desenvolvido através dos meios virtuais para a solução de problemas do mundo real. O conhecimento está na essência dos seres humanos, e a aplicação desses métodos de compartilhamento no dia a dia permite um ciclo contínuo para aplicação da gestão do conhecimento. Reconhecer a importância do papel do conhecimento e da coletividade é um importante esforço que deve ser encarada como a construção de uma base duradoura e sólida para a democracia.

\section{O Governo e o Desafio da Web Social}

A universalização do acesso do cidadão à Internet e às novas ferramentas de comunicação eletrônica é requisito essencial para o desenvolvimento do governo eletrônico e uma sociedade com igualdade. Dessa forma a inclusão digital possibilitará uma substancial ampliação do acesso à informação para o exercício dos direitos de cidadania e para a educação, cultura e entretenimento [22].

\subsection{O Governo em Rede (e-governo)}

O e-governo, ou governo eletrônico refere-se ao uso de tecnologias de informação e comunicação para aumentar a eficiência e a eficácia da gestão pública, melhorar a qualidade dos serviços e informações prestados aos cidadãos, e promover a transparência do setor público e a participação da sociedade. Essa concepção se insere numa perspectiva avançada de governança democrática, transparente e aberta à participação do cidadão.

A redução dos custos da tecnologia e da evolução dos softwares de código aberto disponível, já está ajudando os governos a enfrentarem os desafios diários no mundo em desenvolvimento.

Governos podem utilizar sistemas eletrônicos de várias maneiras como o armazenamento de informações em um formato digital reduzindo a quantidade de papel utilizado e tornando mais fácil o acesso à informação. As utilizações de plataformas eletrônicas também permitem contribuir para um melhor planejamento e controle das despesas públicas. Portais de Internet podem ajudar a economizar tempo e dinheiro em serviços como obtenção de licenças comerciais, recolhimento de impostos entre 
outros eliminando dias e dias de caminhadas desnecessárias ou filas intermináveis. Permite uma integração dos serviços dos serviços de estados e municípios e o governo federal.

No Brasil, o programa e-Brasil se posiciona no marco de visões de futuro que incluem o uso intensivo das TICs no desenvolvimento sócio econômico do país até 2015. O cenário desejável vislumbra o Brasil como um global player capaz de utilizar a tecnologia mais avançada para atacar com sucesso suas mazelas sociais ao mesmo tempo em que se torna um participante de peso do mercado internacional, exportando em quantidade e qualidade software, hardware e soluções em TICs. Para mobilizar o apoio político necessário à concretização desse cenário otimista, é fundamental o desenvolvimento de um consenso nacional. Para tal será necessária a mobilização dos diversos segmentos do setor TIC e também de um debate nacional em torno do "e-desenvolvimento", mobilizando não somente as elites e lideranças políticas como também a população em geral. O que é possível realizar, como fazê-lo, e o que isso vai significar para a melhoria da vida dos brasileiros e suas futuras gerações. Essas são questões que precisam ganhar visibilidade pública cada vez mais ampla, num debate democrático. Também é importante formar lideranças nacionais com bom conhecimento das possibilidades das TICs, da economia política e de modernas técnicas da administração pública [22].

Para alcançar os objetivos do programa e-Brasil e promover a inclusão digital brasileira será necessário por parte do governo investimentos em uma infra-estrutura constituída por redes terrestres e satélites interligados.

A universalização do acesso à Internet e às novas ferramentas de comunicação eletrônica para o cidadão é requisito essencial para o desenvolvimento do governo eletrônico, comércio eletrônico e sociedade eletrônica com igualdade [22]. A inclusão digital é o meio e política públicas através da qual será possível uma real ampliação do acesso à informação para que se possas exercer os direitos de cidadania, a educação, a cultura e entretenimentos. As novas tecnologias representam fator impulsionador e facilitador da redução da exclusão sócioeconômica, por meio da inclusão digital implementada na forma de soluções criativas e democráticas, inseridas em um processo mais amplo de desenvolvimento econômico em sintonia com a construção da sociedade da informação [22].

Os sistemas informatizados relevantes para a prestação de serviços prioritários ao cidadão e para a gestão das políticas públicas, bem como os de apoio à gestão que inclui planejamento, orçamento, administração financeira, serviços gerais e pessoal devem estar alinhados a uma estratégia de integração que proporcione o progressivo compartilhamento de dados e a interligação dos fluxos de processos. A integração possibilita a obtenção de avanços palpáveis na prestação de serviços ao cidadão e na melhoria da qualidade do processo decisório. Além disso, impulsiona o redesenho de estruturas de processos envolvendo unidades administrativas, órgãos e diferentes níveis de governo [22].

A base física para o desenvolvimento do governo eletrônico requer a implantação de infra-estrutura de rede de alto desempenho, integrada e implantada por todo o território nacional, formando um espaço de comunicação e trabalho coletivo virtual, com impacto sobre o desempenho das políticas públicas e da prestação de serviços à sociedade. Essa infra-estrutura poderá ser mantida sob formatos que permitam a racionalização de custos com redução substancial de despesas de telefonia e de acesso à rede. Além disso, permite incorporar a comunicação telefônica convencional a um patamar tecnológico superior, oferecendo formas avançadas de comunicação multimídia.

Um exemplo recente foi a reativação da Telebrás como meio para levar banda larga a um custo reduzido para as área menos favorecidas onde a iniciativa privada possui menor interesse exploratório. As metas do governo é levar a banda larga para mais de 23 milhões de residências, ou seja, quase que triplicando a base atual que é de 12 milhões.

O governo eletrônico, ou e-governo, é uma concepção que assimila os potenciais da TICs na transformação da administração pública, com substancial melhoria da sua organização, dos seus serviços e do relacionamento com a sociedade. Essa concepção se insere numa perspectiva avançada de governança democrática, transparente e aberta à participação do cidadão [22].

A política de governo eletrônico deve ser inserida na agenda prioritária do governo federal e dos governos estaduais e municipais em alinhamento com outras políticas voltadas para o avanço em direção à sociedade da informação. Deve ser orientada por uma visão estratégica e apoiada em instância de coordenação governamental dotada de mandato e capacidade de ação, articulada com os demais níveis de governo e com a sociedade. As empresas públicas de informática e as unidades administrativas de informática dos órgãos e entidades também devem ser alinhadas com a política de governo eletrônico e reestruturadas para a atualização de suas tecnologias e forma de atuação [22].

O governo eletrônico possibilita a evolução para um novo padrão de relacionamento do cidadão com a administração pública. Esse padrão tem como avanços a oferta de serviços e informações na Internet, 24 horas por dia, durante os sete dias da semana, sob múltiplas formas de acesso: computador pessoal, TV Digital interativa, terminais públicos de acesso, terminais de bancos e empresas prestadoras de serviços, telefone, aparelhos móveis como o telefone celular e a PDA, fax e correios [22]. A maior parte das de mandas por serviços e informações padronizados poderá ser atendida por meio desses novos canais viabilizados pela tecnologia da informação. $\mathrm{O}$ atendimento presencial deverá ser mantido, porém direcionado para as demandas de alta complexidade, oferecendo personalização e maior qualidade.

A implementação do governo eletrônico amplia e aprofunda as possibilidades e formatos de abertura de 
informações pelo governo sobre suas decisões de política, serviços, trâmites administrativos, orçamento, execução financeira e processo decisório. Essa abertura deve ser compatível com a preservação da segurança, da privacidade e do interesse público. Portais de transparência na Internet e a extração de relatórios e indicadores dos sistemas informatizados de gestão da administração pública são poderosas ferramentas de promoção da transparência pública [22]. Práticas de governança eletrônica podem ser desenvolvidas na forma de consultas pela Internet e divulgação contínua de informações para as comunidades de política em cada segmento de atividade do governo.

A disponibilização de uma infra-estrutura de comunicação intensiva abrangendo o conjunto da administração pública representa um incentivo à proliferação de arranjos organizacionais que coordenem transversalmente os servidores e gerentes públicos e suas equipes, ultrapassando as barreiras formais entre os órgãos e entidades. Formatos organizacionais em rede poderão proliferar, gerando ganhos em agilidade e desempenho, além de impulsionar a redistribuição de poder nas organizações públicas, atenuando a verticalização e hierarquização das estruturas tradicionais.

As compras e contratações governamentais podem ser realizadas com utilização intensiva de tecnologia da informação, transitando na sua totalidade por sistema informatizado integrador de todas as etapas do processo, com ganhos expressivos de eficiência, desempenho e transparência. A implementação de práticas avançadas de fornecimento tem nos sistemas informatizados um fator crucial para sua viabilização.

\subsection{Comunidades, Participação e E-Governo}

O conceito de inclusão digital está intimamente ligado a questão da inclusão social. O conceito de exclusão digital moldou a compreensão das pessoas da relação da tecnologia com o desenvolvimento. A exclusão digital é em outras palavras, a visão de que a simples presença ou ausência de uma tecnologia através da distribuição de hardware, software e disponibilidade de redes on-line, tem uma influência determinante no comportamento social e no seu desenvolvimento.

A educação de qualidade é uma meta universal, e como instituições de ensino preparam os alunos para uma era de mudanças explosivas e currículos também deve refletir expansão da fronteira do conhecimento.

A exclusão digital é real e favorece a falta de informação. A falta de tecnologias fundamentais relacionados com as competências, tais como usar o mouse, sabe digitar, usar o e-mail, localizar informações na web, e usar processamento de texto e programas de planilha eletrônica é uma indicação clara da necessidade de uma atenção política para esta questão.

Dado que a tecnologia continua a permear nossa existência cotidiana, torna-se necessário possuir um computador apenas para competir no mundo de hoje. Informação é conhecimento e conhecimento é poder.
Hoje, a sociedade passou de uma sociedade industrial para uma sociedade da informação. Proficiência em tecnologia tornou-se um imperativo econômico. O mundo dos negócios já adotou a tecnologia, tanto que trabalhar futuro exigirá cada vez mais conhecimentos de informática.

Segundo estudo mais recente, a empresa de estatística comScore Inc divulgou que o total de internautas no Brasil ultrapassou 73 milhões de usuário no mês de maio de 2010. Esses dados contabilizam os acessos em diversos ambientes, como cybercafés, lan-houses, universidades e telecentros, além de residências e estações de trabalho. Dados do IBGE (Instituto Brasileiro de Geografia e Estatística) do final de 2009 mostram que o acesso em casa e lan-house superaram o número de acesso em locais de trabalho devido ao aumento da renda do brasileiro. Porém dados do mesmo IBGE mostram que para $74 \%$ da população que ainda não possui um computador, o preço ainda é o principal obstáculo para não possuírem o equipamento $\mathrm{e}$ consequentemente, não terem acesso ao ambiente virtual.

Segundo dados da UIT (União Internacional de Telecomunicações), o preço médio cobrado no Brasil para uma conexão de $256 \mathrm{Kbps}$ no ano de 2009 era de US\$ 28,03, o que representa quase a metade do preço cobrado em 2008, porém o brasileiro paga $43 \%$ em impostos para ter acesso à rede. Os dados indicam também que no ano de 2011, $80 \%$ do país estarão cobertos por infra-estruturas de rede.

A presença da tecnologia permite que as pessoas expandam e proporcionam novas oportunidades de aprendizagem independentes do quanto o acesso é distribuído. Há ainda um número muito grande de centros urbanos desfavorecidos, com um grande número de trabalhadores não qualificados, jovens e adultos com pouca educação, e recursos financeiros limitados. A principal causa da exclusão digital é a falta de acesso à informação e formação para o emprego de alta tecnologia. A tecnologia pode se tornar a força que proporciona um acesso equitativo às oportunidades educacionais para todos, independentemente da sua localização, social, econômica e circunstância. Devido a este fato, a educação tornou-se um processo ao longo da vida. Muitas organizações estão tentando fornecer treinamento e acesso à tecnologia, onde ocorre a formação da educação digital. Para ser habilitada, as pessoas precisam de treinamento e apoio técnico para dominar novas tecnologias. Portanto a capacitação tecnológica torna-se essencial em uma democracia, porque permite aos indivíduos uma iteração com a sociedade moderna e proporciona um futuro mais promissor de igualdade.

As questões de tecnologia e inclusão social surgem em diversos contextos. Eles podem ser rotulados em recursos físicos, recursos digitais, recursos humanos, e recursos sociais.

Os recursos físicos englobam acesso a computadores e conexões de telecomunicações. Já os recursos digitais referem-se ao material digital que é disponibilizado online. Os recursos humanos giram em torno de questões 
como alfabetização e educação (incluindo os tipos particulares de práticas de alfabetização que são exigidos para o uso do computador e comunicação on-line). Recursos sociais referem-se à comunidade, institucionais e estruturas sociais de apoio acesso às tecnologias da informação e comunicação (TIC).

Ao considerar estes quatro conjuntos de recursos, é importante a perceber sua relação com o uso repetitivo das TIC. Se por um lado, cada um dos recursos é um colaborador eficaz na utilização das TIC. Em outras palavras, a presença desses recursos ajuda a garantir que as TIC possam ser bem utilizadas e exploradas. Por outro lado, o acesso a cada um destes recursos é resultado do uso efetivo das TIC. Em outras palavras, o uso das TIC pode assim ajudar a estender e promover o acesso a esses recursos.

Se bem tratado, estes recursos podem assim servir como um círculo virtual que promove o desenvolvimento social com recursos que permitem a utilização da tecnologia no desenvolvimento social. Porém se mal utilizada, esses elementos podem servir como um ciclo vicioso do subdesenvolvimento e da exclusão.

Portanto, a inclusão digital deve ser tratada como um elemento constituinte da política de governo eletrônico, para que esta possa configurar-se como política universal. Esta visão funda-se no entendimento da inclusão digital como direito de cidadania e, portanto, objeto de políticas públicas para sua promoção [8].

Entretanto, a articulação à política de governo eletrônico não pode levar a uma visão instrumental da inclusão digital. Esta deve ser vista como estratégia para construção e afirmação de novos direitos e consolidação de outros pela facilitação de acesso a eles. Não se trata, portanto, de contar com iniciativas de inclusão digital somente como recurso para ampliar a base de usuários e, portanto, justificar os investimentos em governo eletrônico, nem reduzi-la a elemento de aumento da empregabilidade de indivíduos ou de formação de consumidores para novos tipos ou canais de distribuição de bens e serviços [8].

Além disso, enquanto a inclusão digital concentra-se apenas em indivíduos, ela cria benefícios individuais, mas não transforma as práticas políticas. Não é possível falar destas sem que se fale também da utilização da tecnologia da informação pelas organizações da sociedade civil em suas interações com os governos, o que evidencia o papel relevante da transformação dessas mesmas organizações pelo uso de recursos tecnológicos [8].

A Internet permite a troca de informações sem levar em conta as fronteiras geográficas. A aprendizagem ao longo da vida tornou-se uma necessidade e habilidades tecnológicas são cada vez mais importante para encontrar um emprego, a falta de acesso à tecnologia reforça os resultados negativos no mercado de trabalho para as pessoas com educação limitada. Em última análise, ninguém deve ser deixado para trás com os avanços da sociedade do século 21, onde ter acesso a computadores e à Internet pode ser a chave para se tornar um membro bem sucedido da sociedade, e com certeza é de fundamental importância para uma maior integração e desenvolvimento do Brasil, aproximando um país de dimensão continental continentais.

\section{A Experiência Colaborativa na Iniciativa do Projeto de Lei da Internet Brasileira}

O uso público da Internet, no Brasil, começou há 15 anos e até hoje não existe uma lei específica sobre o assunto. O discurso de que a "Internet é um lugar sem regras" em breve deixará de fazer sentido, pois o objetivo do Marco Civil é fazer com que a legislação reconheça a natureza e os princípios da web.

\subsection{A Iniciativa do Marco Civil da Internet Brasileira}

Para atender a uma demanda da sociedade civil, o Ministério da Justiça, representado pela sua Secretaria de Assuntos Legislativos, em parceria com o Centro de Tecnologia e Sociedade da Escola de Direito do Rio de Janeiro, da Fundação Getúlio Vargas, criaram um grupo de trabalho com o objetivo de implementar um processo colaborativo, onde toda a sociedade brasileira foi convidada a participar do desenvolvimento de um projeto de lei que visa definir a regulamentação da Internet Brasileira, propondo as responsabilidades de cada um: o usuário, o provedor, e o conteúdo.

Surgiu-se uma grande oportunidade para editar uma norma que pudesse atualizar o horizonte do direito para a cultura digital, respeitando os direitos dos indivíduos, adequando o direito à natureza da rede mundial, definindo com clareza as responsabilidades dos diversos atores envolvidos e estabelecendo diretrizes para a atuação governamental, garantia do pleno acesso, integração e interoperabilidade.

Desde o princípio, o objetivo do marco civil não foi o de restrição o acesso ou uso da Internet e também não se optou por normatizar localmente aquilo que dependia de harmonização internacional para funcionar. Os objetivos traçados pelo grupo de trabalho para a discussão do Marco civil foram [21]:

1) definir diretrizes claras para a ação governamental tanto no que diz respeito à regulação quanto no que tange a formulação de políticas públicas para a Internet;

2) reconhecer, proteger e regulamentar direitos fundamentais dos indivíduos, bem como estabelecer com clareza a delimitação da responsabilidade civil daqueles que atuam na rede como prestadores de serviço; e

3) estabelecer balizas jurídicas que permitissem ao judiciário atuar com precisão e de forma fundamentada para a resolução de conflitos envolvendo a utilização da rede.

Alguns temas como certificação digital, comércio eletrônico, comunicação eletrônica em massa, crimes praticados por meio da Internet, definição técnica sobre os tipos de serviço de telecomunicações, direito autoral, governança e gestão político-administrativa da Internet, 
gestão de protocolo Internet (IP) e regulamentação de lan houses, dialogam com o Marco Civil, porém não fazem parte da discussão por já serem parte de discussões devidamente estruturadas em outros âmbitos e portanto e não fazem parte do objetos de regulamentação pelo anteprojeto de lei do Marco Civil. Esses temas já possuem outros fóruns de discussão institucionalizados no congresso ou na sociedade ou já fazem parte de projetos de lei em tramitação, ou de alguma forma já estão consolidados em leis, decretos e outras normas.

Também é importante não confundir o objetivo Marco Civil com o os objetivos do Comitê Gestor da Internet no Brasil (CGI.BR), órgão responsável pela governança da Internet no Brasil e que coordena e integra todas as iniciativas de serviços Internet no país, promovendo a qualidade técnica, a inovação e a disseminação dos serviços ofertados.

A discussão sobre marco civil é pautada, tanto em sua forma quanto em seu conteúdo, pelas premissas expostas pelo CGI e um dos objetivos do debate foi definir em que medida tais princípios deveriam ser consolidados em nível legal, e em que medida mereceriam ser desdobrados em regulamentação mais clara, para afirmação de direitos. Esses princípios são [24]:

1) Liberdade, privacidade e direitos humanos - o uso da Internet deve guiar-se pelos princípios de liberdade de expressão, de privacidade do indivíduo e de respeito aos direitos humanos, reconhecendo-os como fundamentais para a preservação de uma sociedade justa e democrática.

2) Governança democrática e colaborativa - a governança da Internet deve ser exercida de forma transparente, multilateral e democrática, com a participação dos vários setores da sociedade, preservando e estimulando o seu caráter de criação coletiva.

3) Universalidade - o acesso à Internet deve ser universal para que ela seja um meio para o desenvolvimento social e humano, contribuindo para a construção de uma sociedade inclusiva e não discriminatória em benefício de todos.

4) Diversidade - a diversidade cultural deve ser respeitada e preservada e sua expressão deve ser estimulada, sem a imposição de crenças, costumes ou valores.

5) Inovação - a governança da Internet deve promover a contínua evolução e ampla difusão de novas tecnologias e modelos de uso e acesso.

6) Neutralidade da rede - filtragem ou privilégios de tráfego devem respeitar apenas critérios técnicos e éticos, não sendo admissíveis motivos políticos, comerciais, religiosos, culturais, ou qualquer outra forma de discriminação ou favorecimento.

7) Inimputabilidade da rede - 0 combate a ilícitos na rede deve atingir os responsáveis finais e não os meios de acesso e transporte, sempre preservando os princípios maiores de defesa da liberdade, da privacidade e do respeito aos direitos humanos.

8) Funcionalidade, segurança e estabilidade - a estabilidade, a segurança e a funcionalidade globais da rede devem ser preservadas de forma ativa através de medidas técnicas compatíveis com os padrões internacionais e estímulo ao uso das boas práticas.

9) Padronização e interoperabilidade - a Internet deve basear-se em padrões abertos que permitam a interoperabilidade e a participação de todos em seu desenvolvimento.

10) Ambiente legal e regulatório - o ambiente legal e regulatório deve preservar a dinâmica da Internet como espaço de colaboração.

Outra premissa do projeto consistia em reconhecer que a legislação brasileira enfrenta lacunas com relação à Internet, com uma série de questões ainda não reguladas. Essas lacunas geram incerteza, com prejuízo para direitos fundamentais dos indivíduos, para a inovação e para a segurança jurídica.

O debate, que foi dividido em duas fases e teve início em 29 de outubro de 2009 quando o Comitê Gestor disponibilizou os tópicos propostos para regulação, a partir de texto-base produzido pelo próprio Ministério da Justiça. O texto base contextualizou e sistematizou os principais temas pendentes de regulação e ofereceu sinalizações sobre os possíveis caminhos a serem trilhados. $\mathrm{O}$ debate ocorreu em torno de idéias, princípios e valores.

O texto base da primeira fase baseou-se em três grandes eixos de discussão: direitos individuais $e$ coletivos, responsabilidade dos diversos atores $\mathrm{e}$ diretrizes governamentais. No primeiro eixo da discussão buscou identificar quais direitos individuais e coletivos relacionados ao uso da Internet atualmente e que não estão previstos de forma explícita nas leis nacionais. Esses direitos são passíveis de proteção, por derivarem de princípios constitucionais, porém a ausência de previsão legal específica para sua proteção a um contexto de comunicação eletrônica pode acabar por prejudicar seu exercício.

Nesse eixo foram discutidas as questões de Privacidade, Liberdade de Expressão e Direto de acesso. Em relação a tema "privacidade", destacaram-se os seguintes pontos:

- A relação entre intimidade e vida privada, direitos fundamentais.

- A inviolabilidade das informações que trafegam na rede.

- A retenção de dados pessoais (guarda de logs) pelos provedores de acesso à Internet e provedores, condições de segurança para sua guarda, os casos em que se permitida são permitido a sua requisição, e as punições para a violação ao sigilo intrínseco de tais dados.

- A garantia da privacidade em um ambiente digital, à vida privada, ao sigilo das comunicações e aos dados pessoais.

Na discussão do tema "liberdade de expressão", destacam-se os seguintes pontos:

- O direito à liberdade de expressão existe conflitos o com outros direitos fundamentais como o anonimato. Direito de resposta; direito de indenização pelos danos morais e materiais sofridos no caso de 
violações de imagem, honra, intimidade ou privacidade.

- O direito de acesso à Internet e produção de conteúdo. Desenvolvimento social e de promoção de justiça social das comunicações pela Internet. A Internet deve se manter uma ferramenta viável para o usuário final, da qual as pessoas possam se valer para construir as soluções e respostas de que precisem. A facilidade do acesso é um pressuposto, que compreende uma infraestrutura adequada igualmente distribuída pelo País, que possibilite a navegação por diversos dispositivos. É essencial a existência de pontos públicos de acesso, e a velocidade do acesso deve acompanhar as evoluções tecnológicas.

No segundo eixo da discussão, buscou-se identificar responsabilidades dos diversos atores participantes do processo de comunicação através da Internet. Dentre eles, incluem-se provedores de acesso, provedores de conteúdo, provedores de serviços, provedores de aplicativos, provedores de hospedagem, os usuários em sua condição de criadores de conteúdos e outros participantes ativos dos processos de comunicação pela Internet. Nesse eixo de discussão buscou-se a definição clara de responsabilidade dos intermediários e a neutralidade da rede, ou seja, a não-discriminação de conteúdos.

A definição da responsabilidade dos intermediários é ainda uma lacuna existente na legislação brasileira e que precisa ser definida urgentemente para que possam ser sanadas as dúvidas sobre o regime de responsabilidades aplicáveis a cada um dos integrantes do processo de comunicação em rede.

É fundamental a não-discriminação de conteúdos, ou seja, a filtragem indevida de conteúdos, pois fere a própria lógica da Internet onde os controles devem ficar nas pontas (o chamado princípio end-to-end), ou seja, com o usuário. Portanto é preciso garantir que não haja interferência dos intermediários e garantir a livre circulação de informações sem sofrer limitação ou controle na transmissão, recepção ou emissão de dados.

O terceiro eixo da discussão buscou-se discutir diretrizes governamentais que pudessem servir de referência para a formulação de políticas públicas e para a posterior regulamentação em nível legal de aspectos relacionados à Internet. Apesar de já existem diretrizes sobre o tema, como as dispostas na Lei Geral das Telecomunicações e na Política Nacional de Informática, de 1984, essas leis encontram-se desatualizadas dentro dos novos e avançados conceitos da comunicação.

É preciso definir políticas públicas para garantir a abertura, ou seja, a Interoperabilidade Plena, Padrões e Formatos Abertos, Acesso a dados e Informações Públicos. Também é preciso garantir a existência de uma infra-estrutura adequada para Conectividade, Aplicações e Conteúdos garantindo o amplo acesso a Internet. Por ultimo deve ser disponibilizada Capacitação para a utilização da Internet como forma de desenvolvimento social e o exercício de cidadania e promoção da cultura.
Ao final desta primeira etapa, o resultado da compilação das participações gerou uma primeira versão da minuta do anteprojeto de lei, que também foi levado à consulta pública, iniciada em abril de 2010 e encerrada no fim de maio de 2010. O conteúdo desta minuta consta de cinco capítulos e 34 artigos, que foram sendo remodelados ao longo das discussões da segunda fase.

O primeiro capítulo trata das disposições preliminares englobando direitos e deveres dos usuários, determina e objetiva a disciplina do uso da Internet e conceitua os termos ligados a tecnologia da Internet. O segundo capítulo defende as garantias dos direitos do usuário como direito de acesso e cidadania, privacidade e liberdade de expressão. Já no terceiro capítulo, trata-se da provisão de conexão e de serviços de Internet identificando a obrigação de guardar apenas os registros de conexão, a responsabilização dos provedores sobre o conteúdo gerado por terceiros, a proibição do monitoramento ou filtragem de informações pelos provedores de serviço, a forma isomórfica ao tratamento de qualquer informação trafegada, o tempo máximo da guarda de registro de acesso, a obrigação de ordem judicial para disponibilização dos registros de acesso e o procedimento de escuta e interceptação de dados. No capitulo quatro é abordada a forma da atuação do poder público na questão da inclusão digital, estratégia de egoverno e abertura de formatos. Por fim, o capítulo cinco trata das disposições finais.

$\mathrm{O}$ debate foi encerrado e todos os conjuntos de informações obtidas através dos debates e contribuições, recebidas pelos diversos meios disponibilizados para a colaboração estão sendo processados e avaliados pelo grupo de trabalho, e darão a cara ao marco regulatório da Internet brasileira.

\subsection{A Organização do Processo de Construção do Marco Civil}

A iniciativa do grupo de trabalho do Marco Civil da Internet Brasileira partiu do pressuposto que a participação popular poderia enriquecer o processo da construção de leis no nosso país. A idéia foi utilizar os princípios colaborativos da Internet e aproveitar o conhecimento coletivo e voluntário para aperfeiçoar a elaboração legislativa no Brasil. Apesar do processo legislativo brasileiro já possuir alguns outros mecanismos de participação popular, como as audiências e consultas públicas, a intenção foi dar um passo mais adiante, e a ferramenta escolhida para que a participação estivesse ao alcance de cada cidadão foi a Internet.

O intuito foi incentivar, através da própria Internet, a participação ativa e direta dos inúmeros atores sociais envolvidos no tema (usuários, provedores, representantes da iniciativa privada e de governo). Para tanto, o processo de construção do marco regulatório utilizou plataformas abertas e ferramentas da Web 2.0, como apoio primordial para o andamento do processo através da Internet.

As plataformas abertas permitem que o acesso à informação esteja ao alcance de todos. Este também é um dos tópicos abordados durante os debates do Marco Civil. 
Já as ferramentas da Web 2.0 permitiram uma aproximação com a sociedade, para que a participação colaborativa do público fluísse através de diversos meios e de forma mais espontânea.

Para a elaboração do projeto do marco civil da Internet, foram disponibilizados dois espaços principais de manifestação, ambos hospedados no portal Cultura Digital (http://culturadigital.br/marcocivil): um blog para os comentários sobre o texto base, notícias e consultas; e o fórum, ou grupo de discussão.

O espaço virtual intitulado de Cultura Digital é um espaço criado pelo Ministério da Cultura a fim de integrar discussões sobre políticas públicas ligadas a cultura digital brasileira.

O blog foi o espaço escolhido para que os temas da consulta fossem abertos em proposições mais diretas e para que tornasse possível um alinhamento dos usuários na colaboração da construção do anteprojeto de lei. O espaço do blog também foi aproveitado para comentar tópicos que ganharam mais destaque, informar sobre o andamento do processo, esclarecer dúvidas frequentes, ajudar a conduzir e coordenar as discussões, disponibilizar links de notícias relacionados ao projeto e divulgação da consolidação dos resultados obtidos.

Por sua vez, o fórum serviu como espaço efetivamente reservado para que os debates e as discussões se desenvolvessem livremente. Cada tópico do texto base da primeira fase e da minuta do projeto de lei da segunda fase foi colocado em debate. No fórum, tornou-se possível a detecção de problemas não abordados no texto base, a indicação de fatos interessantes, o desenvolvimento de uma dinâmica de argumentação e contra argumentação e a formação de dissensos e consensos.

Iniciado o debate, cada um dos tópicos foi aberto para inserção de comentários por usuários "logados" através do portal Cultura Digital. A função destes comentários foi informar e posicionar junto ao grupo de trabalho, o governo e aos demais debatedores, a posição do usuário sobre determinado assunto em particular garantindo assim uma maior pluralidade de opiniões.

Também foi disponibilizada uma opção de participação, que permitia que cada participante pudesse votar e classificar, positiva ou negativamente, as contribuições dos demais. Segundo o grupo de trabalho, esses votos não significariam, necessariamente, a inclusão ou exclusão de determinado tópico do debate e serviram apenas para nortear a equipe de redação sobre as preferências, opiniões e interesses dos participantes, contribuindo para a formulação da proposta.

Além dos dois espaços principais (o blog e o fórum) do portal da Cultura Digital, um aparato de ferramentas gratuitas foi integrado ao portal através dos serviços conhecidos como RSS feeds. Dessa forma, foi permitida uma maior e melhor distribuição da informação e divulgação do processo do marco regulatório, aproximando a participação dos colaboradores com a utilização de ferramentas de alto índice de acesso, e que fazem parte do seu dia a dia da maioria dos internautas.
Algumas dessas ferramentas foram integradas ao longo do processo por sugestão dos próprios colaboradores.

Outras ferramentas da Web 2.0 também foram integradas ao portal da Cultura Digital e, de alguma forma, colaboraram para o processo de construção do Marco Civil:

- Uma ferramenta interessante permitida por blogs é conhecida como trackback, um rastro que permite notificar o autor quando um link para seu texto é citado em outro lugar na rede. Desta forma, a equipe do marco civil pode tomar conhecimento de comentários, opiniões e posições sobre o processo de construção do marco civil da Internet apresentadas na "blogosfera" e que de alguma forma fizeram links diretos com o debate.

- Tumblr é uma plataforma de blogging que permite aos usuários publicarem textos, imagens, vídeo, links, citações e áudio. Ela é um blog de textos curtos, mas não chega a ser um microblog, estando em uma categoria intermediária entre. Os usuários são capazes de "seguir" outros usuários e ver seus posts em seu painel (dashboard). Eles podem gostar ("favoritar") ou "reblogar" (divulgar) outros blogs.

- Facebook, uma rede social onde os usuários criam perfis com fotos e listas de interesses pessoais, trocando mensagens entre si, foi mais uma forma usada para a divulgação do projeto do Marco Civil.

- Delicious, site que oferece serviço on-line que permite ao usuário adicionar e pesquisar bookmarks sobre qualquer assunto, é mais do que um mecanismo de buscas para encontrar o que se quer na web. Ele é uma ferramenta para arquivar e catalogar os sites preferidos para que o usuário possa acessálos de qualquer lugar e foi mais uma forma de facilitar o acesso ao portal da Cultura Digital.

- Twitter é rede social e servidor para microblogging que permite aos usuários enviarem e receberem atualizações pessoais de outros contatos (em textos curtos, conhecidos como tweets), por meio do website do serviço, por SMS e por softwares específicos de gerenciamento. As atualizações são exibidas no perfil de um usuário em tempo real e também enviadas a outros usuários seguidores que tenham assinado para recebê-las. Os twitters foram integrados a cada tópico do blog e do fórum onde eram possível que os usuário postassem seus comentários sobre o debate.

- Google Bookmarks, serviço voltado aos usuários que preferem manter seus favoritos on-line.

Como resultado dessas contribuições coletivas, o texto aos poucos foi se modificando. Novos parágrafos, tópicos ou eixos puderam ser incluídos, conforme a demanda, pertinência e desdobramento das discussões. Essas modificações e inclusões foram notificadas por meio do blog do Marco Civil, que pode ser acessado na página de abertura.

A partir das discussões sobre o texto base, disponibilizado na primeira fase, e a partir dos comentários recebidos com teses afirmativas ou negativas de direitos, responsabilidades e obrigações, que indicava 
o que cada manifestante acha que deve ou não ser garantido ou regulado no âmbito da Internet, as contribuições foram lidas e processadas pela equipe do Marco Civil dando origem a primeira versão da minuta do anteprojeto de lei.

\subsection{A Participação da Sociedade}

Para garantir que a elaboração do Marco Civil fosse um processo democrático e aberto, foi montado todo um aparato de recursos como os descritos na seção 4.2 deste artigo, permitindo atingir o maior número possível de interessados, mesmo que estes recursos não fossem primordiais para a sua conclusão.

A idéia foi exatamente a de abrir para o público a construção do projeto de lei para poder captar efetivamente as demandas sociais. Portanto era muito importante que a própria sociedade se mobilizasse para conversar sobre os seus interesses e para discutir os direitos, as garantias e as responsabilidades pertinentes. $\mathrm{O}$ importante era que fosse possível ouvir o maior número de vozes, e para isso a participação popular era fundamental.

A formulação do Marco Civil para a Internet brasileira foi um processo colaborativo que pode ser tomado de exemplo para outras iniciativas similares. A rede social Cultura Digital hoje agrega cerca de cinco mil usuários e três mil blogs cadastrados, com 280 grupos de discussão para os mais diversos temas do universo da cultura digital, segundo dados de maio de 2010.

Durante a primeira fase, dados divulgados pelo próprio Ministério da Justiça revelaram que só durante os 20 primeiros dias da primeira fase, o blog criado para a discussão recebeu mais de 120 mil acessos e 433 comentários de internautas. Ao final desta primeira fase, o número de comentário ultrapassou os 800 que foram divulgados em um relatório de 581 páginas.

Os assuntos mais comentados pelos usuários neste período foram o acesso anônimo, a guarda de registros de acesso, ampliação da banda larga, liberdade de expressão na Internet e privacidade. Convém lembrar que cada uma das fases foi aberta por 45 dias para o debate público.

A segunda fase de debates foi concluída com um total de 1.168 contribuições à minuta, feitas no blog. Durante esse período de consulta, houve 59,3 mil acessos à minuta. Os pontos mais debatidos foram a importância da minuta em si, a necessidade ou não de um marco civil para a Internet, a discussão sobre a guarda de registros, a responsabilização dos provedores e a retirada de conteúdo de sites, blogs, entre outros. Por outro lado, apenas quatro comentários foram feitos sobre o uso da Internet como ferramenta educacional.

Além das contribuições diretas no blog, as ferramentas de Microblog Twitter receberam mais de 1200 posts ou menções de apoio ou divulgação. Esses comentários também foram compilados e disponibilizados em um relatório de 60 páginas.

Durante todo o processo um grande número de usuários da Internet participou ativamente do processo colaborativo garantido uma grande diversidade de opiniões positiva ou negativamente. Uma ampla participação da sociedade e das instituições responsáveis pela administração da justiça no processo de construção do marco civil da Internet foi fundamental para garantir a pluralidade de visões e opiniões.

O Marco Civil também foi notícia em de reportagens na TV, na Web e em outros meios de comunicação. Virou tema de fóruns, debates e palestras em diversos eventos nacionais e internacionais em universidades, seminários, congressos e audiências publicas.

Também foram solicitadas, através do Ministério de Relação Exteriores às embaixadas brasileiras em diversos países do mundo, informações sobre a existência de leis regulamentação da Internet em cada um destes lugares sobre a guarda dos registros de acesso, as responsabilidades dos provedores e o direito ou vedação ao anonimato na rede. Dentre as contribuições internacionais recebidas estão as embaixadas dos seguintes países: Arábia Saudita, África do Sul, Argélia, Argentina, Áustria, Bahamas, Cingapura, Chile, China, Colômbia, Dinamarca, Espanha, Espanha, Estados Unidos, Estônia, Guiana, Grécia, Guiné, Israel, Itália, Japão, Jordânia, México, México, Namíbia, Suécia, Suíça e Uruguai.

O Brasil não é o primeiro país a criar normas para regular a utilização da Internet, e também não são apenas países de regime socialistas, como a China e Coréia do Norte ou países islâmicos como Irã, que têm normas para controlar o uso da Internet. Diversos países do mundo já sentiram a necessidade de autorregulamentação do ambiente virtual que é cada vez mais utilizado e extrapola suas fronteiras geográficas.

Em âmbito de um bloco continental, a União Européia possui um marco próprio e unificado para a proteção de dados pessoais, e editou medidas tanto para a proteção das pessoas com relação ao tratamento de seus dados pessoais (1995), quanto para o tratamento de dados pessoais e proteção da privacidade no setor das comunicações eletrônicas (2002). A União Européia também conta com diretiva específica para a regulamentação da internet, datada de 2006. Independentemente de seu conteúdo, é importante perceber que a diretiva apenas foi editada após a consolidação de uma regulamentação sobre o tratamento de dados pessoais (inclusive em forma eletrônica), que estabeleceu limites claros à proteção deste direito fundamental [21]. Além das diretivas da União Européia, vários países membros do bloco, possuem diretivas complementares a essas normas como é o caso da Suécia, Espanha e Dinamarca.

A China é o caso de um país que restringe fortemente o uso da Internet por lei, desde 1994. O governo chinês advoga, ostensivamente, o "uso racional da tecnologia para coibir a disseminação de informação ilegal na rede". A política chinesa de administração da Internet tem sido caracterizada pelo controle e filtragem das informações transmitidas, com o bloqueio do acesso a sites com conteúdo ilegal, tais como aqueles que contrariem os princípios constitucionais, ameacem a segurança do Estado e a unidade nacional, perturbem a ordem pública, 
ameacem a política religiosa oficial, disseminem pornografia, incentivem delitos, como cassinos virtuais, entre outros. Na prática, as autoridades chinesas têm interpretado de modo abrangente o que seria esse conteúdo ilegal, restringindo o acesso a diversas páginas da rede. Entre esses, encontram-se desde sites pornográficos, websites de instituições de direitos humanos até sites de relacionamento populares como o Youtube, o facebook e o twitter.

Japão, outro país asiático considerado conservador e altamente conectado a Internet não tem lei específica de regulamentação da Internet. A regulação é feita por uma ampla gama de leis e resoluções. Para questões específicas, relacionadas às responsabilidades dos provedores de serviços, existe a "Lei de Limitação de Responsabilidade Civil de Provedores".

Nos Estados Unidos, a exemplo do que ocorreu no Brasil com o Marco Civil, a Federal Communications Commission (FCC), órgão regulador das telecomunicações, iniciou em julho de 2010, consulta pública sobre o assunto. $O$ órgão quer identificar um "caminho legal" para regulamentar a Internet, tendo em vista a implantação de um plano nacional de banda larga no país. O propósito do órgão com a consulta é avançar em sua missão de transformar a Internet de alta velocidade em um serviço de telecomunicações, sujeitando-a a regulamentações mais estritas.

A obrigatoriedade de guarda de registros é um assunto é debatido no Congresso norte-americano desde 2008. A proposta atende a demanda do FBI que, desde 2005, propugna pela adoção de regra que obrigue os provedores de acesso a reter, por pelo menos dois anos, para fins de investigação criminal, os registros de acesso de seus usuários. Mais recentemente, outras agências de aplicação da lei (Serviço de Imigração do Departamento de Segurança Interna e autoridades policias dos estados) passaram a apoiar publicamente o pleito do FBI.

Em relação ao anonimato no acesso à Internet há entendimento jurisprudencial de que a primeira emenda à Constituição norte-americana, que garante a liberdade de expressão, protege também o direito ao anonimato. A Electronic Communications Privacy Act (ECPA), de 1986, estabelece provisões para a proteção de acesso, uso, divulgação, interceptação e privacidade de comunicações por meio eletrônico, aplicável a várias formas de transmissão de dados. O anonimato, entendido como proteção da fonte de certa manifestação ou expressão online, não se aplica, no entanto, para fins de investigação e execução da lei.

$\mathrm{Na}$ América Latina, em países como Argentina, Uruguai e Colômbia não existem leis específicas que regulamentam a Internet. O Uruguai até segue na contramão e proíbe completamente a guarda de $\log$ por parte dos provedores. Já o Chile saiu na frente e aprovou em agosto de 2010 a primeira lei de defesa da neutralidade do mundo. O Boletin 4915 garante o acesso a todo tipo de conteúdo, serviços ou aplicativos disponíveis na rede, sem distinção de fonte de origem ou propriedade.

\subsection{Estágio Atual do Marco Civil}

Em 31 de maio de 2010 chegou ao fim a $2^{\text {a }}$ fase de debate aberto do processo colaborativo de discussão e formulação do Marco Civil para a Internet brasileira. Após todo o processo de consulta pública, o processo se encontra em fase de consolidação das contribuições recebidas.

As inúmeras contribuições recebidas precisam ser processadas e ponderadas para que se chegue a um consenso para a apresentação de um texto final que represente claramente as necessidades da sociedade e se apresente com conceitos modernos e contemporâneos de forma a atender a necessidade para se legislar sobre um mundo sem fronteiras.

A idéia é que o grupo de trabalho do Marco Civil gerasse a versão final do anteprojeto lei a ser enviada à câmera legislativa até o final do primeiro semestre, dada o possível o impacto das eleições de 2010 no trabalho. Porém até final de agosto de 2010, não havia sido apresentado nenhum relatório final de conclusão do trabalho ou apresentação do texto final do anteprojeto de lei da internet brasileira.

\section{Conclusões}

Em muitos países democráticos, a regulação da Internet ocorreu em um quadro puramente legislativo, com a maioria das tentativas de aperto da censura e controle acentuado com violação da liberdade de expressão e das liberdades privadas. Em contrapartida, o projeto Marco Civil da Internet Brasileira teve como prerrogativa absoluta o acesso à Internet como um direito cívico fundamental, essencial para a expressão da cidadania e da liberdade de expressão e acesso à informação. Portanto é fundamental compreender a necessidade de políticas públicas que garantam o processo de inclusão digital viabilizando meios de acesso para a inserção da população nesse novo ambiente de cultura digital.

A utilização da própria Internet como meio de regulamentá-la foi um convite aberto para um processo democrático. A estruturação do processo com base em ferramentas abertas e gratuitas da Web 2.0 foi uma experiência inovadora para as práticas de e-governo, permitindo uma maior aproximação da população as iniciativas governamentais.

A presença das tecnologias da Web 2.0 ofereceu a facilidade e a interatividade necessárias para que o processo colaborativo fluísse naturalmente. Além disso, essas ferramentas garantiram uma grande audiência no processo, pois, fazem parte do dia a dia das pessoas que utilizam o ambiente virtual.

Durante o período em que o debate permaneceu aberto foram recebidas e debatidas uma variedade de opiniões. Ou seja, o aproveitamento do conhecimento coletivo foi fundamental para se obter um termômetro do sentimento de cada um dos interessados para, então, se chegar às conclusões para a formulação do texto base 
final. Participaram destes debates empresas privadas, órgãos públicos e milhares de anônimos.

De acordo com [25]: "Um dos maiores desafios do mundo contemporâneo, senão o maior deles, é o de zelar para que a camada de identidade da Internet reflita adequadamente o complexo de atributos de todos aqueles que por ela são tangidos. Há de se cuidar para que redes de colaboração não se transformem em redes de juízo de valor e para o linchamento injustificado de pessoas".

A partir da experiência pioneira do Marco Civil, a rede Cultura Digital tornou-se referência para a realização de novas consultas públicas abertas e participativas. Mais do que uma plataforma de simples interação com usuários na Internet, o conjunto de softwares que possibilitou a consulta pública do Marco Civil da Internet Brasileira tornou-se um ambiente de construção colaborativa, extrapolando limites da construção legislativa na democracia, através de tecnologia livre.

Uma nova consulta pública para revisão da lei de direito autoral já foi iniciada. Este será o segundo processo legislativo colaborativo realizado em parceria com a Coordenação de Cultura Digital do Ministério da Cultura, seguindo os mesmos modelos dos processos interativos organizado para a construção do Marco Civil .

\section{Referências Bibliográficas}

[1] Tim O'Reilly. What is web 2.0, http://oreilly.com/web2/archive/what-is-web-20.html, 18 junho 2010.

[2] Tim O'Reilly. Web 2.0 Compact Definition: Trying Again, http://radar.oreilly.com/.../web-20-compact-definitiontryi.html, 18 junho 2010.

[3]How Business are Using a Web 2.0: A Mckinsey Global Survey,

www.mckinseyquarterly.com/How_businesses_are_using Web_20_A_McKinsey_Global_Survey_1913, 18 junho 2010.

[4] Gomez de la Torre, Valerie. Knowledge Management Systems Research Paper: Knowledge Management Systems and Web 2.0 Tools \& Technologies, School of Information, the University of Texas at Austin December 8 th , 2005

[5] Warschauer, Mark. A Sociedade da Informação, 19: $297-$ 304, 2003 Departamento de Educação, Universidade da Califórnia, E.U.A.

[6] Block Eastern, Judy. Educação a Distância e da exclusão digital: uma perspectiva acadêmica, Michigan University, E.U.A.

[7] Cresce o número de usuários de Tecnologias da Informação no país, http://www.inclusaodigital.gov.br/noticia/cresce-onumero-de-usuarios-de-tecnologias-da-informacao-no-pais, 01 de agosto 2010.

[8] Principios e Diretrizes, http://www.governoeletronico.gov.br/o-gov.br/principios, 29 julho 2010.

[9] Brasil tem 73 milhões com acesso à internet, http://www.expressomt.com.br/noticia.asp?cod=76834\&cod $\underline{\mathrm{Dep}=8}, 02$ julho 2010.

[10] Warschauer, Mark. The Information Society, 19: 297-304, 2003. Department of Education, University of California, USA.
[11] Inclusão digital, educação e desenvolvimento econômico: alguns marcos do debate Revista FAMECOS - Porto Alegre - $\mathrm{n}^{\mathrm{o}} 33$ - agosto de 2007

[12] A Inclusão Digital é indissociável do Governo Eletrônico. Extraído de: BRASIL. Oficinas de Planejamento Estratégico - RELATÓRIO CONSOLIDADO - Comitê Executivo do Governo Eletrônico, Maio de 2004, pp. 12-14.

[13] Zack H., Michael. Gerenciando conhecimento codificado, Volume 40, N 4, 1999, pp. 45-58, setembro de 1998.

[14] Z. Shariq, Syed. Knowledge Management: An Emerging Discipline and a Professional Society for Facilitating Adaptive Change to a Stable World Order in the 21st Century, Macau, July 2-4, 1997.

[15] T. Knight,Peter. Gestão do Conhecimento e do governo eletrônico no Brasil Fórum Global sobre Reinvenção do Governo, 26-29 Junho de 2007, Viena, Áustria. www.eBrasil.org.br, 22 junho de 2010.

[16] Yendis. Um programa para acelerar o desenvolvimento socioeconômico aproveitando a convergência digital, São Caetano do Sul, SP, 2006.

[17] Lemos Pinto, Solon. Web 2.0 no Governo: Práticas de Gestão da Informação no Relacionamento do Governo com a Sociedade, 13 de Novembro de 2009.

[18] Simões, Luís; e Borges Gouveia , Luís Web 2.0 e do Ensino Superior: Implicações Pedagógicas, Universidade Fernando Pessoa, Portugal, 2008.

[19] Brasil ultrapassa a marca de 26 milhões de acessos à internet, http://www. infomoney.com.br, 11 de agosto de 2010.

[20] Renda do brasileiro ainda é insuficiente para arcar com os custos de uma banda larga, http://www.infomoney.com.br, 13 de agosto de 2010.

[21] Debate do processo de construção do projeto de lei do Marco Civil da Internet Brasileira, http://culturadigital.br/marcocivil, 29 de outubro de 2009 a 30 de maio de 2010.

[22] Programa e-Brasil, http://www.e-brasil.gov.br, 28 de junho de 2010.

[23] A Inclusão Digital é indissociável do Governo Eletrônico http://www.computadoresparainclusao.gov.br/, 24 de julho de 2010

[24]Regulamentação, http://www.cgi.br/regulamentacao/index.htm, 29 de julho de 20

[25] Secretaria de Assuntos Legislativos do Ministério da Justiça (2010). Marco Civil da Internet: Seus direitos e deveres em discussão. Relatório - Compilação de Comentários apresentados na primeira etapa. Janeiro (in http://culturadigital.br/marcocivil/consulta/), 6 de outubro de 2010 